\title{
Challenges in Elimination of Filariasis: New Foci of B. Malayi Infection in Odisha, India
}

\author{
Nilam Somalkar', Sushanta Kumar Kar', Sudhansu Sekhar Mishra ${ }^{3}$, Nupur Roy", \\ Madan Mohan Pradhan ${ }^{5}$, Arun Sivan ${ }^{6}$, Rajendran R7 $\underline{\text { Pasi AR }}^{8}$
}

${ }^{1}$ Regional Director, ${ }^{2,3}$ Regional Office of Health and Family Welfare, Bhubaneswar, Odisha, India.

${ }^{4}$ Additional Director, NVBDCP, New Delhi, India.

${ }^{5}$ Additional Director (VBD), Boudh, Odisha Government, Odisha, India.

${ }^{6}$ Entomology Consultant, State NVBDCP, Odisha, India.

${ }^{7}$ Deputy Director, NCDC, Kozhikode, Kerala, India.

${ }^{8}$ Airport Health Organization, Mumbai, Maharashtra, India.

DOI: https://doi.org/10.24321/0019.5138.202102

\section{I $\quad \mathbf{N} \quad \mathbf{F} \quad \mathbf{O}$}

\section{Corresponding Author:}

Nilam Somalkar, Regional Office of Health and Family Welfare, Bhubaneswar-751014, Odisha, India

E-mail Id:

nilam.80@gov.in

Orcid Id:

https://orcid.org/0000-0003-2976-5309

How to cite this article:

Somalkar N, Kar SK, Mishra SS, Roy N, Pradhan MM, Sivan A et al. Challenges in Elimination of Filariasis: New Foci of B. Malayi Infection in Odisha, India. J Commun Dis 2021; 53(1): 5-9.

Date of Submission: 2020-12-29

Date of Acceptance: 2021-03-03

\section{$\begin{array}{llllllllllll}\mathbf{A} & \mathbf{B} & \mathbf{S} & \mathbf{T} & \mathbf{R} & \mathbf{A} & \mathbf{C} & \mathbf{T}\end{array}$}

Background: Odisha was endemic for B. malayi along with W. bancrofti for Lymphatic Filariasis, but since 2004, there was no evidence of B. malayi in Elimination of Lymphatic Filariasis (ELF) program. We conducted the present study to reconfirm the presence of B malayi in Baleswar and Bhadrak districts of Odisha.

Methods: We conducted a night blood survey in 12 villages of Baleswar and 11 villages of Bhadrak district of Odisha in June 2017. Villages were selected purposively based on highest morbidity of reported lymphatic filariasis. A total of 6230 and 5606 blood slides were collected in Baleswar and Bhadrak districts respectively. Data was analyzed by using Microsoft Excel, 2007. Results were presented in the form of rates \& ratios appropriately. Chi square, students' $t$ ' test \& SEP was used as test of significance and $p \leq 0.05$ was considered statistically significant.

Results: In Baleswar and Bhadrak district $0.99 \%$ and $0.43 \%$ of the slides were positive for microfilariasis (Mf). In Baleswar district Mf was detected in $83.3 \%$ of villages and in 5 villages the Mf infection rate was more than 1 percent. In Bhadrak district Mf was detected in $72.7 \%$ of villages and in 2 villages the Mf infection rate was more than 1 percent. In Baleshwar and Bhadrak district $98.4 \%$ and $33.3 \%$ of positive slides were due to $B$ malayi infection and the difference was statistically significant $(p<0.001)$. The difference in the age and sex wise distribution was statistically insignificant.

Conclusion: Present study confirms the presence of B malayi infection in Baleshwar and Bhadrak districts of Odisha.

Keywords: Microfilariasis, B Malayi, W Bancrofti, Lymphatic Filariasis, ELF, MDA 


\section{Introduction}

Filariasis has been a major public health problem in India. The disease was recorded in India as early as 6th century B.C. by the famous Indian physician, Susruta in his book 'Susruta Samhita'.1,2 In India, the disease is endemic in 256 districts across 21 States/ UTs (16 States \& 5 UTs). The population at risk is about 630 million. ${ }^{3,4}$

Filariasis is the common term for a group of diseases caused by parasitic nematodes belonging to super family Filarioidea. Adult worms of these parasites live in the Iymphatic system, cutaneous tissues or body cavity of the humans and are transmitted through vectors. Filariasis caused by nematodes that live in the human lymph system is called Lymphatic Filariasis (LF), commonly known as elephantiasis. ${ }^{3,4}$

Three nematode parasites causing LF in human are Wuchereria bancrofti, Brugia malayi and Brugia timori. In India, $99.4 \%$ of the LF cases are caused by the species - Wuchereria bancrofti whereas $0.6 \%$ of cases are due to Brugia malayi. $^{2-4}$

Wuchereria bancrofti, transmitted by the ubiquitous vectors: Culex quinquefasciatus. It breeds preferably in dirty polluted waters, but in the absence of it they can breed in clean wateralso. Mansonia (Mansonioides) annuliferais the principal vector and $\mathrm{M}$. uniformis is the secondary vector for transmission of B. malayi infection. The breeding of these mosquitoes is associated with aquatic plants such as Pistia stratiotes, Salvinia auriculata, Salvinia molestes, Eichhornia speciosa, E. crassipes, etc. Both W. bancrofti and B. malayi infections in mainland India exhibit nocturnal periodicity of microfilariae. ${ }^{3,5}$

B. malayi infects 13 million people in South and South-East Asia and is responsible for nearly $10 \%$ of the world's total cases of lymphatic filariasis. B. malayi infection is endemic or potentially endemic in 16 countries, where it is most common in Southern China and India, but it also occurs in Indonesia, Thailand, Vietnam, Malaysia, the Philippines, and South Korea. ${ }^{6,7}$

Reports of Brugia malayi infection have been documented earlier in some rural areas of seven states viz., Kerala, Odisha, Tamil Nadu, Andhra Pradesh, Madhya Pradesh, Assam and West Bengal. However, its prevalence is now limited to rural areas of Kerala and in some pockets in other states.5, 8 As per the historical records, Odisha was endemic for B. malayi, but since 2004, there was no evidence of B. malayi in Elimination of Lymphatic Filariasis (ELF) program. ${ }^{4,9}$

During the cross-check examination of additional random site survey of 10 randomly selected villages in both districts at $\mathrm{ROH}$ and FW Bhubaneswar, B. malayi was detected in 04 slides of two villages in Baleswar and 03 slides of two villages in Bhadrak district. We conducted the present study to reconfirm the presence of $B$ malayi in two districts namely Baleswar and Bhadrak in view of ELF.

\section{Objectives}

- To reconfirm the presence of B malayi infection in Baleswar and Bhadrak districts of Odisha

- To study the microfilariasis infection rate in Baleswar and Bhadrak districts of Odisha

- To study the age and sex wise distribution of the $B$ malayi infection in Baleswar and Bhadrak districts of Odisha

\section{Methods}

We conducted the present study in Baleswar and Bhadrak districts of Odisha by doing a field-based survey. Survey was designed and conducted by a team of experts from NVBDCP, VCRC Pudduchery, ROH \& FW Bhubaneswar and NCDC, Kozhikode. We conducted the study in 12 and 11 purposively selected villages from Baleswar and Bhadrak districts respectively. All these selected villages had reported highest morbidity of Lymphatic Filariasis. We decided to collect blood samples for Mf slides from 500 or more individuals from each village. The sample size of $500 \mathrm{Mf}$ slides from each village was calculated conveniently as it was sufficient to study the stated objectives and draw the logical conclusions.

During the survey a total of 6230 blood slides were collected from 12 villages in Baleswar district and 5606 blood slides were selected from 11 villages in Bhadrak district. The survey was conducted in the month of June 2017 with the help of the team consisting of LT, Health worker, ANM and ASHA of the village.

Blood slides were collected from all age groups in the selected survey villages from 8:30 pm onwards. After collection of $\mathrm{Mf}$ slides from each village, staining was carried out in Central lab of NVBDCP, Odisha under the guidance of ROH\&FW Bhubaneswar using JSB stain and stained slides were examined by NCDC units at Varanasi, Rajahmundry and Kozhikode.

Permission for the study was obtained from the appropriate authorities. The information obtained during the survey was kept confidential and not shared or used for any other purpose. The study participants found positive for Mf were referred for appropriate treatment and further management.

We analyzed data using Microsoft Excel, 2007. The results were presented in the form of rates \& ratios appropriately. Standard error of difference between two proportions was used to compare the slide positivity rate \& B malayi infection rate, chi square test was used to study the difference in the sex wise distribution and student's ' $t$ ' rest was used to 
study the difference in the age wise distribution. The value of $p \leq 0.05$ was considered statistically significant.

\section{Result}

A total of 6230 and 5606 blood slides were collected from 12 villages in Baleswar districts and 11 villages in Bhadrak district. Out of total 6230 slides collected in Baleswar district 62 (0.99\%) slides were positive for Mf. Out of total in Bhadrak district 24 were positive for Mf. Slide positivity rate in Baleswar district was more as compare to the slide positivity rate in Bhadrak district and the difference in the proportion was statistically highly significant $(p<0.001)$ (Table 1).

Table I.District wise distribution of slide positivity rate

\begin{tabular}{|c|c|c|}
\hline $\begin{array}{c}\text { Name of the } \\
\text { district }\end{array}$ & $\begin{array}{c}\text { Total Mf slides } \\
\text { collected }\end{array}$ & $\begin{array}{c}\text { Total slides } \\
\text { positive }\end{array}$ \\
\hline Baleswar & 6230 & $62(0.99 \%)$ \\
\hline Bhadrak & 5606 & $24(0.43 \%)$ \\
\hline
\end{tabular}

Table 2.Site wise distribution of Mf rate in Baleswar district

\begin{tabular}{|c|c|c|c|c|}
\hline S. No. & $\begin{array}{c}\text { Village } \\
\text { name }\end{array}$ & $\begin{array}{c}\text { Blood } \\
\text { slides } \\
\text { examined }\end{array}$ & $\begin{array}{c}\text { Slide } \\
\text { positive } \\
\text { for Mf }\end{array}$ & $\begin{array}{c}\text { Mfrate in } \\
\text { percentage }\end{array}$ \\
\hline 1. & Rapeya & 539 & 09 & 1.67 \\
\hline 2. & Dagara & 502 & 04 & 0.79 \\
\hline 3. & Chaumukh & 538 & 00 & 0.00 \\
\hline 4. & Betagadia & 520 & 06 & 1.15 \\
\hline 5. & Ratai & 536 & 02 & 0.37 \\
\hline 6. & Nuagaon & 516 & 16 & 3.10 \\
\hline 7. & Ada & 504 & 02 & 0.39 \\
\hline 8. & Panchupali & 507 & 09 & 1.78 \\
\hline 9. & Balikuti & 511 & 10 & 1.96 \\
\hline 10. & Pratappur & 564 & 02 & 0.36 \\
\hline 11. & Khirkona & 489 & 02 & 0.41 \\
\hline 12. & Bhikagadia & 504 & 00 & 0.00 \\
\hline & Total & 6230 & 62 & 0.99 \\
\hline
\end{tabular}

In Balswar district, more than 500 blood slides were collected from each of the selected 11 villages while from 1 village Khirkona only 489 blood slides were collected. In 10 (83.3\%) out of 12 villages Mf was detected, however in 2 villages (Chaumukh and Bhikagadia) Mf was not detected in any of the blood slides. Over all Mf rate was 0.99 percent and 5 villages (Rapeya, Betagadia, Nuagaon, Panchupali and Balikuti) hadMf rate more than 1 percent. Mf rate was maximum (3.1\%) in Nuagaon village (Table 2).

In Bhadrak district, more than 500 blood slides were collected from each of the selected 11 villages. In 8 (72.7\%) out of 11 villages $\mathrm{Mf}$ was detected, however in 3 villages (Chaumukh and Bhikagadia) Mf was not detected in any of the blood slides. Over all Mf rate was 0.43 percent and 2 villages (Korkara and Bandola) had Mf rate more than 1 percent. Mf rate was maximum (1.51\%) in Korkara village (Table 3).

Table 3.Site wise distribution of Mf rate in Bhadrak district

\begin{tabular}{|c|c|c|c|c|}
\hline $\begin{array}{c}\text { S. } \\
\text { No. }\end{array}$ & $\begin{array}{c}\text { Village } \\
\text { name }\end{array}$ & $\begin{array}{c}\text { Blood } \\
\text { slides } \\
\text { examined }\end{array}$ & $\begin{array}{c}\text { Slide } \\
\text { positive } \\
\text { for Mf }\end{array}$ & $\begin{array}{c}\text { Mf rate in } \\
\text { percentage }\end{array}$ \\
\hline 1. & $\begin{array}{c}\text { Kherualpur } \\
\text { \& Khempur }\end{array}$ & 514 & 02 & 0.39 \\
\hline 2. & Makhalpur & 500 & 01 & 0.20 \\
\hline 3. & Bramangan & 505 & 01 & 0.20 \\
\hline 4. & Urnia & 502 & 02 & 0.40 \\
\hline 5. & Khadiapada & 501 & 00 & 0 \\
\hline 6. & Sohada & 503 & 02 & 0.40 \\
\hline 7. & Palikiri & 500 & 01 & 0.20 \\
\hline 8. & Korkara & 530 & 08 & 1.51 \\
\hline 9. & Bandola & 519 & 07 & 1.35 \\
\hline 10. & Routraipur & 522 & 0 & 0 \\
\hline 11. & Sendhatira & 510 & 0 & 0 \\
\hline & Total & 5606 & 24 & 0.43 \\
\hline
\end{tabular}

Table 4.District wise distribution of slide positivity rate for B malayi

\begin{tabular}{|c|c|c|}
\hline $\begin{array}{c}\text { Name of the } \\
\text { district }\end{array}$ & $\begin{array}{c}\text { Total slides } \\
\text { positive for Mf }\end{array}$ & $\begin{array}{c}\text { Slides positive for } \\
\text { B malayi }\end{array}$ \\
\hline Baleswar & 62 & $61(98.4 \%)$ \\
\hline Bhadrak & 24 & $08(33.3 \%)$ \\
\hline
\end{tabular}

In Baleswar district out of total 62 slides positive for $\mathrm{Mf}$, $61(98.4 \%)$ slides were positive for B malayi and 1 (1.6\%) slide was positive for $\mathrm{W}$ bancrofti. In Bhadrak district out of total 24 slides positive for Mf, 08 (33.3\%) slides were positive for $B$ malayi and $16(66.7 \%)$ slides were positive for $\mathrm{W}$ bancrofti. $\mathrm{B}$ malayi infection rate was more in Baleswar district and this difference in proportion was statistically highly significant $(p<0.001)$ (Table 4).

Out of total 86 slides positive for Mf 69 (80.2\%) slides were positive for $B$ malayi infection. Out of these 69 slides positive for B malayi infection 61 (88.4\%) were from Baleswar district and $08(11.6 \%)$ were from Bhadrak district. Out of total 69 persons positive for B malayi infection 43 (62.3\%) were male and 26 (37.7\%) were females. Mean age was 43 years however it ranges from 4 years to 82 years. 
Table 5.Age and Sex wise distribution of B Malayi cases

\begin{tabular}{|c|c|c|c|c|c|}
\hline & \multicolumn{2}{|c|}{ District Name } & \multirow{2}{*}{ Total $(\mathrm{N}=69)$} & \multirow{2}{*}{ P value } \\
\hline & & Baleswar $(\mathrm{N}=61)$ & Bhadrak $(\mathrm{N}=08)$ & & \\
\hline \multirow{2}{*}{ Age in years } & Mean $\pm S D$ & $42 \pm 19.62$ & $49 \pm 13.7$ & $43.04 \pm 19.07$ & \multirow{2}{*}{0.18} \\
\hline & Range & 4 to 82 & 27 to 70 & 4 to 82 & \\
\hline \multirow{2}{*}{ Sex } & Male n (\%) & $37(60.6)$ & $06(75)$ & $43(62.3)$ & \multirow{2}{*}{0.43} \\
\hline & Female $\mathrm{n}(\%)$ & $24(39.4)$ & $02(25)$ & $26(37.7)$ & \\
\hline
\end{tabular}

In Baleswar district out of total 61 persons infected with B malayi 37 (60.6\%) were males while in Bhadrak district out of total 08 persons infected with B malayi $06(75.0 \%)$ were males and this difference was statistically insignificant $(p=0.43)$. In Baleswar district mean age of the persons infected with B malayi was 42 years with SD of 19.62 while in Bhadrak district mean age of persons infected with $B$ malayi was 49 years with SD of 13.7 years and this difference was statistically insignificant ( $p=0.18$ ) (Table 5 ).

\section{Discussion}

Baleswar and Bhadrak districts are endemic for LF and were covered under annual round of MDA from 2004. These districts conducted 10 rounds of MDA using DEC and Albendazole. Main parasite for LF was W. Bancrofti. Baleswar and Bhadrak districts achieved Mf rate of $<1 \%$ in 2015 and 2016 respecticely. ${ }^{4}$ Overall slide positivity rate was 0.73 percent and it was significantly more in Baleswar district as compare to the Bhadrak district. Similar study conducted by Gyan Chand et al in Madhya Pradesh in the year 2013, found that the slide positivity rate was 0.8 percent. Gyan Chand et al also reported new foci of B Malayi infection in Madhya Pradesh. ${ }^{10}$

In Baleswar district 5 villages and in Bhadrak district 3 villages had slide positivity rate more than 1 percent. Though it is known that five to six rounds of treatment with more than $65 \%$ of population coverage for MDA compliance could possibly eliminate the disease by reducing transmission to very low levels. The evaluation of MDA coverage in India and also in south India indicated that the compliance rates were not at desirable. ${ }^{9,11,12}$

Out of all cases positive for $\mathrm{Mf}$, more than $80 \%$ were due to B Malayi infection. In Baleswar district proportion of B malayi infection was as high as 98.4 percent. Both Baleswar and Bhadrak districts are coastal districts of Odisha with lots of rivers and tributaries falling in the Bay of Bengal and the areas are highly vulnerable to flood during rainy season. Therefore, the habitants of the locality used to make their basement of the house little high by ditching ponds nearby the house to get rid of flood. Later the pond becomes an indispensable property of the habitants as it provides fish to their food basket. Besides these in villages, ponds are being used by community for household water source and for bathing purpose also. In the due course of time the ponds are flooded with aquatic vegetation such as Pistia and Eichhornia plants which are highly conducive for breeding of vector for B.malayi i.e. Mansonia. The main occupation of population is farming and fishing. ${ }^{13,14}$ The nocturnal form of brugian filariasis is more common and is transmitted in areas of coastal rice fields (by Mansonia and Anopheles mosquitoes), whereas the subperiodic form is found in the swamp forests (Mansonia vector). ${ }^{15}$ Both districts Baleswar and Bhadrak have the environmental factors very much favorable for breeding of the vector Mansonia and Anopheles which makes them vulnerable for high burden of $L F$ including $B$ malayi.

Though the B malayi infection rate was significantly higher in Baleswar district as compare to the Bhadrak district however there was no difference in the age and sex was distribution of B malayi infection. In the year 2006 the study conducted by Kalyani Rath et al in Odisha reported that there was no difference in knowledge and perception of men and women about lymphatic filariasis however level of education was significantly associated with the knowledge and perception. Education level and socioeconomic status of the people in both the districts are almost similar. ${ }^{13,14,16}$

In Baleswar and Bhadrak district, B malayi infection was proportionately high inspite of having good coverage of MDA and Transmission Assessment Surveys (TAS). The clinical presentations of B malayi cases are very mild as compare to the W Bancrofti cases because of which during surveys it is very less likely to get the $B$ malayi cases reported. The main clinical difference between brugian and bancroftian filariasis is the absence of hydroceles and other genital lesions and chyluria in areas endemic for $\mathrm{B}$. malayi. Lymphoedema of the legs in Brugia infections usually does not extend above the knee whereas both the thigh and lower leg are often involved in bancroftian filariasis. Lymphoedema of the legs and arms seem to be both more common and less severe in brugian filariasis than in bancroftian filariasis. Acute adenitis of femoral lymph nodes is common in brugian filariasis and these may suppurate and drain pus, either spontaneously or following treatment with anti-filarial medications. ${ }^{17}$ 


\section{Conclusion}

The study confirms the presence of B malayi foci in Baleswar and Bhadrak districts of Odisha, India. It is recommended that more of such surveys to be carried out in other districts of Odisha as well as in parts of India to achieve the goal of elimination of lymphatic filariasis.

\section{Acknowledgement}

We thankfully acknowledge the hardwork done by the night survey team including ASHAs, ANMs, Laboratory Technicians and the participants. Our special thanks to, VCRC Puducherry and Incharge, NCDC, Rajamundri, Kazhikode and Varanasi for their valuable support.

\section{Source of Funding: None}

\section{Conflict of Interest: None}

\section{References}

1. Bhaskar C, Harinath, Reddy MVR. Filariasis in India. Journal International Medical Science 2000; 13: 8-12.

2. Agarwal VK, Sashindran VK. Lymphatic Filariasis in India: Problems, Challenges and New Initiatives. Medical Journal of Armed Forces India (MJAFI) 2006; 62: 359-62.

3. Park K. Parks Textbook of Preventive and Social medicine. 25 $5^{\text {th }}$ ed. Banarsidas Bhanot, Jabalpur. 2019.

4. Ministry of Health and Family Welfare, Government of India. Disease Control Programmes (NHM). Annual Report 2018-19; 73-75.

5. Sabesan S, Palaniyandi M, Das PK et al. Mapping of lymphatic filariasis in India. Ann Trop Med Parasitol 2000; 94: 591-606.

6. Remme JHF, Feenstra P, Lever PR et al. Tropical diseases targeted for elimination: Chagas disease, lymphatic filariasis, onchocerciasis, and leprosy. Disease Control Priorities in Developing Countries 2006.

7. Chang MS. Operational issues in the control of the vectors of Brugia. Annals of Tropical Medicine and Parasitology 200; 96(2): 571-6.

8. Hati AK, Chandra G, Bhattacharrya A et al. Annual transmission potential of bancroftian filariasis in an urban and a rural area of West Bengal, India. Am J Trop Med Hyg 1989; 40: 365-7.

9. Babu BV, Behera DK, Kerketta AS et al. Use of an inclusive partnership strategy in urban areas of Orissa, India, to increase compliance in a mass drug administration for the control of lymphatic filariasis. Annals of Tropical Medicine and Parasitology 2006; 100: 621-630.

10. Chand G, Barde PV, Singh N. Emergence of new foci of filariasis in Madhya Pradesh, India. Transactions of the Royal Society of Tropical Medicine and Hygiene 2013; 107(7): 462-4.

11. Ramaiah KD, Kumar KNV, Ramu K. Knowledge and beliefs about transmission, prevention and control of lymphatic filariasis in rural areas of South India. Tropical Medicine and International Health 1989; 1: 433-8.

12. Babu BV, Satyanarayana K. Factors responsible for coverage and compliance in mass drug administration during the programme to eliminate lymphatic filariasis in the East Godavari district, South India. Tropical Doctor 2003; 33: 79-82.

13. Geography of Baleswar district. 2020. Available on https://en.wikipedia.org/wiki/Balasore_district.

14. Geography of Bhadrak district. 2020. Available from: https://en.wikipedia.org/wiki/Bhadrak_district.

15. Nutman TB. In The Travel and Tropical Medicine Manual. Fifth Edition, 2017; 574-587.

16. Rath K, Mishra S, Nath $\mathrm{N}$ et al. Knowledge and perceptions about lymphatic filariasis: a study during the programme to eliminate lymphatic filariasis in an urban community of Orissa, India. Tropical Biomedicine 2006; 23(2): 156-162.

17. Simonsen PE, Fischer PU, Hoerauf A et al. Manson's Tropical Infectious Diseases. Twenty-third Edition, 2014; 737-765. 